\title{
The relationship between y balance performance and hip strength in recreationally trained women
}

\author{
Relação entre desempenho no y balance test e força de quadril em mullheres recreacionalmente \\ treinadas
}

Relación entre y balance test y fuerza em mujeres recreacionalmente entrenadas

\begin{abstract}
This study set one's sight on the relationship between lower quarter y balance test (YBT-LQ) score with hip isometric strength with recreationally resistance-trained women. Utilizing dynamic balance as a screening tool for lower extremity injury risk has been proposed as a potential solution in injury prevention and injury assessment. A convenience sample of twenty young college females $(22.3 \pm 2.1$ years) with a background in regular strength or plyometric training volunteered to participate in this study. The scores of YBT-LQ for each direction were calculated. A hand-held dynamometer was used to measure the maximum voluntary isometric strength of each participant's unilateral hip extensors, flexors, adductors, abductors, internal and external rotation muscles. Significant lower normalized score was noted for the dominant limb $(81.2 \pm 11.7)$ when compared to non-dominant limb $(83.6 \pm 12.4)$ for anterior distance. For the composite score of YBT-LQ, a weak association was noted for hip extension andinternal rotation, and moderate association was observed for hip flexion, adduction, and abduction. On the other hand, a strong association was observed between hip external rotators strength $(r=0.516)$. Thus, the main finding of the current study was the strong associationobserved between hip external rotators strength and composite score of YBT-LQ.
\end{abstract}

Keywords: Dynamic balance; Injury risk; Resistance training.

\section{Resumo}

O texto objetivou avaliar a relação entre o desempenho no $Y$ balance test para membros inferiores (YBT-LQ) com a força isométrica da musculatura do quadril em mulheres recreacionalmente treinadas no treinamento de força. Utilizar o equilíbrio dinâmico como ferramenta de avaliação para risco de lesão dos membros inferiores tem sido proposto como possível solução para prevenção ou avaliação de lesões. Uma amostra selecionada por conveniência composta por 20 mulheres em idade universitária $(22.3 \pm 2.1$ years) com histórico regular de prática em exercícios de força e 
pliométricos voluntariaram-se para este estudo. As pontuações no YBT-LQ foram aferidas nas três direções. Um dinamômetro portátil foi utilizado para aferir a contração isométrica voluntária máxima dos extensores, flexores, adutores, abdutores, rotadores internos e externos do quadril. Um score normalizado significativamente inferior foi observado para o membro dominante $(81,2 \pm 11,7)$ comparado ao não dominante para o alcance anterior. Para o score composto uma associação fraca foi observada junto aos extensores e rotadores internos de quadril e uma moderada associação observada para flexores, adutores e abdutores de quadril. Por outro lado, uma forte associação foi observada para os rotadores externos $(\mathrm{r}=0,516)$. Portanto, o principal achado do presente estudo foi a forte associação entre rotadores externos do quadril e o score composto do YBT-LQ.

Palavras-chave: Equilíbrio dinâmico; Lesão; Treinamento de força.

\section{Resumen}

El texto tuvo como objectivo evaluar la relación entre el $Y$ balance test (ybt=lq) y fuerza isométrica de las caderas en mujeres entrenadas en entrenamiento de fuerza. Utilizar el equilibrio dinámico como una herramienta de evaluación del riesgo de lesiones en las extremidades inferiores. Una muestra de conveniencia con 20 mujeres estudiantes universitarias con experiencia en entrenamiento de fuerza y pliometría participaron en el estudio. Se calcularon las puntuaciones de YBT-LQ para cada dirección. Se utilizó un dinamómetro de mano para medir la fuerza isométrica voluntaria máxima de los extensores, flexores, aductores, abductores y músculos de rotación internos y externos de la cadera unilaterales de cada participante. Se observó una puntuación normalizada significativamente más baja para el miembro dominante $(81,2 \pm 11,7)$ en comparación con el miembro no dominante $(83,6 \pm 12,4)$ para la distancia anterior. Para la puntuación compuesta de YBT-LQ, se observó una asociación débil para la extensión de la cadera y la rotación interna, y se observó una asociación moderada para la flexión, aducción y abducción de la cadera. Por otro lado, se observó una fuerte asociación entre la fuerza de los rotadores externos de la cadera $(\mathrm{r}=0,516)$. Por tanto, el principal hallazgo del presente estudio fue la fuerte asociación observada entre la fuerza de los rotadores externos de la cadera y la puntuación compuesta de YBT-LQ.

Palabras clave: Balance dinámico; Lesión; Entranamiento de fuerza.

\section{Introduction}

Dynamic balance is an integral component when examining lower extremity injury risk considering that the neuromuscular system has an important role n dynamic stability (Riemann \& Lephart, 2002). Utilizing dynamic balance as a screening tool for lower extremity injuries has been proposed as a potential solution in injury avoidance and injury assessment (Brech, et al., 2013). Hip abductor and external rotator muscle strength play a major role in reducing knee adduction and internal rotation torque (Kendall, et al., 2005). Specifically, hip abductor and external rotator muscle strength deficits are associated with the femoral position of adduction and internal rotation torque at the knee (dynamic knee valgus) and consequently affect hip dynamic balance (Gordon, et al., 2013).

An increasing number of studies have attempted to identify variables related to dynamic balance, static balance, and ankle range of motion (ROM) aiming to predict lower extremity injuries in physically active populations (Paz, et al., 2016, Williams, et al., 2016). One instrument utilized to examine dynamic balance is the Lower Quarter Y Balance Test (YBT-LQ). The YBT-LQ is a platform apparatus variant of the Star Excursion Balance Test (SEBT), employing three of the original eight reaching directions: anterior, posteromedial and posterolateral (Wilson, et al., 2018). This dynamic balance instrument incorporates standardized height, stance foot placement and reaching measurements. The YBT-LQ has been verified as a reliable test with a high proficiency of inter and intra-rater reliability (McCann, et al., 2017). The benefits of the YBT are that it has a standard protocol and high inter-rater (0.99-1.00) and intra-rater (0.85-0.91) reliabilities (Linek, et al., 2017).

Wilson et al. (2018) examined the relationship between elements of isometric hip strength and the Y Balance Test, to provide clinicians better guidance as to specific areas of muscle performance to address in the event of poor performance on the Y Balance Test. The authors found significant positive correlations between Y- Balance Test performance and hip abduction strength. They also found correlations between the Y-Balance Test and hip extension and external rotation strengths. Hartley et al. (2018) investigated static balance, dynamic balance, ankle range of motion, body mass index (BMI), or history of an ankle sprain were all associated with ankle sprain injuries within collegiate athletes of both sexes. 
They noticed that male collegiate athletes with greater BMI and lesser YBT-LQ anterior reach were at a greater risk of sustaining an ankle sprain injury.

Understanding the dynamic balance framework for each particular population allows for specific standard performance evaluation points to be established. Although the authors understand that the relationship between dynamic balance and isometric strength is already established, we consider it relevant to address this topic exclusively to recreationally. Thus, this evidence may help conditioning professionals and practitioners during the training prescription and assessment. Therefore, the purpose of this study was to identify the relationship between YBT-LQ score with hip isometric strength with recreationally resistance trained college women

\section{Methodology}

\subsection{Experimental design}

This was an experimental qualitative research whose sample was selected for convenience (Medronho, et al., 2009).

\subsection{Participants}

Twenty young college females with background in regular strength or plyometric training volunteered to

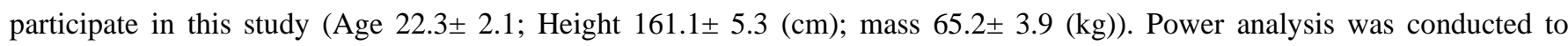
determine sample size (n) using Cohen's d (Cohen, 2013) of 1.1-1.3 for improvements in muscular performance. Sample size was calculated revealing that each group required between 13 and 15 participants to meet the required power of 0.8 at an alpha value of $p<0.05$. All participants had at least three years of resistance training experience ( $3.5 \pm 1.2$ years), averaging 60 -min per sessions three times a week. All participants were active in competitive sports training or were active in actual competition one to four times per week. The exclusion criteria adopted for the current research was: (a) potential medical problems such as joint injuries or a history of ankle, knee or back pathology that compromised their participation or performance during the proposed tests; (b) any lower extremity surgery in the prior two years.

\subsection{Protocol}

Participants indicated their "dominant limb" by answering which leg they would use to kick a ball. Limb testing was randomized. Prior to data collection, the participants were informed about the experimental procedures and about possible risks and benefits associated with their participation in the study and signed an informed consent before any of the tests performed. Procedures were approved by the Institutional Ethics Review Committee of the University in accordance with the current national and international laws and regulations governing the use of human subjects (Declaration of Helsinki II).

Y balance test (YBT-LQ) measurement: Participants completed the YBT-LQ using a metric tape fixed on the floor in a manner previously described in the literature (Ganesh, et al.,2015; Gordon, et al., 2013; Johnston, et al., 2018). The participants stood with one leg -the stance leg- on the starting position, and used their opposite leg, the reaching leg, to touch as far as possible with the halux in the anterior, posterolateral, and posteromedial directions sustaining the farthest reach for at least two seconds. Attempts did not count if the participant was unable to maintain a single leg stance throughout the entire movement, rested the left foot out of the mark while reaching, elevated the suporting ankle in an attempt to gain extra distance, or the participant did not return to starting position with maintained balance. Each participant completed three testing trials in each direction with each legfter completing six practicing trials, which were included to familiarize the participant with the testing maneuvers. One-minute rest between repetitions was adopted to prevent fatigue. Only values from the three testing trials were used to calculate the subject's scores. 
Scores for each direction (anterior, posteromedial, and posterolateral) were calculated by dividing the average reach distance (in cm) by the participant's leg length (in cm) and multiplying by 100 (Paz, et al., 2017). The patient's leg length was measured from the most prominent aspect of the anterior-superior iliac spine to the distal tip of the ipsilateral medial malleolus. To calculate the composite score, the sum of maximum reaches in each directions was divided by three times the leg length (Paz, et al., 2017).

Handheld dynamometer: A MicroFet 2 hand-held dynamometer (Hogan Health Industries, Inc. 8020 South 1300 West, West Jordan, USA) was used to measure the maximum voluntary contraction. The rater was a physical education professional with five years of experience in testing procedures. The maximal isometric contraction of the unilateral hip extensors, flexors, adductors, abductors, internal and external rotation was adopted following procedures suggested by Kendall et al (2005). Participants were told to stop contracting when the tester finished counting to five seconds (Williams, et al., 2016). This duration was shown to be adequate for most subjects in order to reach the maximum force (Douma, et al., 2014). The mean peak value of these three trials for each muscle group was used for the data analysis.

\subsection{Statistical Analysis}

All statistical analysis were performed using SPSS 23 Statistics Software (SPSS Inc. Chicago, IL). Data were tested for normality using the Shapiro-Wilk test. Mean and standard deviations were calculated for each of the variables, on each leg. T-tests were performed to determine if there were any between limb differences of the dominant and non-dominant leg. Pearson correlation coefficients were calculated between the three hip strength measurements and the Y-Balance test scores. To describe the strength of the correlation, the following scale was used for the absolute value of the correlation coefficient (r): strong relationship $(0.50 \leq \mathrm{r} \leq 1.0)$, moderate relationship $(0.3 \leq \mathrm{r}<0.5)$, and weak relationship $(\mathrm{r}<0.3)$ (Hopkins, et al., 2009). The level of significancefor all analysis was set at $\mathrm{p} \leq 0.05$.

\section{Results and Discussion}

No difference between dominant and non-dominant limb was noted for posterolateral and posteromedial parameters of YBT-LQ (Table 1 provided for observation). However, a significant lower score was noted for dominant limb when compared with the non-dominant limb for anterior distance. No difference between limbs was observed for all hip strength evaluation applied in the present study.

Table 1 - Mean and standard deviation of hip strength and Y-balance parameters between dominant and non-dominant limb

\begin{tabular}{lccc} 
& Dominant limb & Non-dominant limb & P value \\
\hline Y-balance test (\% leg length) & & \\
Anterior & $81.2(11.7)$ & $83.6(12.4)^{*}$ & 0.050 \\
Posterolateral & $111.5(16.2)$ & $107.5(13.3)$ & 0.068 \\
Posteromedial & $103.1(16.5)$ & $103.1(13.2)$ & 0.544 \\
Composite & $120.8(21)$ & $120.6(19.5)$ & 0.871 \\
Isometric strength (N) & & & \\
Hip flexion & $19.9(7.9)$ & $18.3(6)$ & 0.772 \\
Hip extension & $20.6(9.8)$ & $19.9(7.9)$ & 0.544 \\
Hip adduction & $12.2(2.7)$ & $11.2(3)$ & 0.083 \\
Hip abduction & $15(3.1)$ & $15.5(3.3)$ & 0.269 \\
Hip internal rotators & $14(4.1)$ & $13.3(4.3)$ & 0.282 \\
Hip external rotators & $11.3(1.7)$ & $10.9(1.7)$ & 0.364 \\
\hline
\end{tabular}

* Significant difference for dominant limb $(p \leq 0.05)$. Source: Authors. 
A weak association was noticed between hip extension, internal rotators and anterior distance of YBT-LQ test (Table 2 provided for observatiob). On the other hand, moderate association was observed between hip extension, adduction, abduction and external rotation with anteriorreach distance. For posterolateral reach distance, a weak association was noted for hip flexion, extension, adduction and abduction (Table 3 provided for observation). However, moderate association was observed for internal and external rotators.

Table 2 - Correlations between anterior distance of y-balance and isometric hip strength.

\begin{tabular}{llll}
\hline & $\mathrm{r}$ & P-value* $^{*}$ & Classification \\
\hline Anterior & & & \\
\hline Hip flexion & 0.404 & 0.152 & Moderate \\
Hip extension & 0.264 & 0.362 & Weak \\
Hip adduction & 0.414 & 0.152 & Moderate \\
Hip abduction & 0.403 & 0.153 & Moderate \\
Hip internal rotators & 0.243 & 0.403 & Weak \\
Hip external rotators & 0.473 & 0.088 & Moderate \\
\hline
\end{tabular}

* Indicates Significant Correlation. Source: Authors.

Table 3 - Correlations between posterolateral distance of y-balance and isometric hip strength.

\begin{tabular}{llll}
\hline & $\mathrm{r}$ & P-value* & Classification \\
\hline Posterolateral & & & \\
\hline Hip flexion & 0.254 & 0.381 & Weak \\
Hip extension & 0.249 & 0.391 & Weak \\
Hip adduction & 0.254 & 0.381 & Weak \\
Hip abduction & 0.228 & 0.432 & Weak \\
Hip internal rotators & 0.423 & .0132 & Moderate \\
Hip external rotators & 0.405 & 0.151 & Moderate \\
\hline
\end{tabular}

* Indicates Significant Correlation. Source: Authors.

For posteromedial reach distance, a weak association was noted for hip flexion, extension, abduction and internal rotation (Table 4 provided for observation). However, moderate association was noted for hip adduction and external rotation. For composite score of YBT-LQ, a weak association was noted for hip extension and internal rotation (Table 5 provided for observation). Moderate association was observed for hip flexion, adduction and abduction. On the hand, the only strong association was observed betweenhip external rotators strength and composite score of YBT-LQ.

Table 4 - Correlations between posteromedial distance of y-balance and isometric hip strength.

\begin{tabular}{llll}
\hline & $\mathrm{r}$ & P-value* & Classification \\
\hline Posteromedial & & & \\
\hline Hip flexion & 0.219 & 0.451 & Weak \\
Hip extension & 0.079 & 0.789 & Weak \\
Hip adduction & 0.357 & 0.210 & Moderate \\
Hip abduction & 0.254 & 0.382 & Weak \\
Hip internal rotators & 0.173 & 0.554 & Weak \\
Hip external rotators & 0.358 & 0.209 & Moderate \\
\hline
\end{tabular}

* Indicates Significant Correlation. Source: Authors. 
Table 5 - Correlations between composite score of y-balance and isometric hip strength.

\begin{tabular}{llll}
\hline & $\mathrm{r}$ & P-value* $^{*}$ & Classification \\
\hline Composite & & & \\
\hline Hip flexion & 0.358 & 0.209 & Moderate \\
Hip extension & 0.263 & 0.364 & Weak \\
Hip adduction & 0.320 & 0.264 & Moderate \\
Hip abduction & 0.414 & 0.141 & Moderate \\
Hip internal rotators & 0.222 & 0.446 & Weak \\
Hip external rotators* & 0.516 & 0.059 & Strong \\
\hline
\end{tabular}

* Indicates Significant Correlation. Source: Authors.

The purpose of this study was to identify the relationship between YBT-LQ score and hip isometric strength in recreationally resistance trained women. The main finding of the current study was the strong association observed between hip external rotators strength and composite score of YBT-LQ. A weak/moderate association was noted between hip flexion, extension, adduction, abduction and internal rotation isometric strength and YBT-LQ reach distances or composite score. These results were partially in agreement with the previous evidences observed in the scientific literature (Brech, et al., 2013; Chen \& Chou, 2017; Culiver, et al., 2019; Linek, et al., 2017; McCann, et al., 2017).

Despite the lack of a significant difference, a strong association between hip external rotation strength and the composite score of YBT-LQ was found in the present study. On the other hand, Gordon et al (2013) examined the relationships between core strength examined through the bent knee lowering test, hip external rotation strength and lower extremity balance measured by the SEBT's composite score in a sample composed by 45 female lacrosse players. Hip external rotator strength was measured singularly via hand held dynamometry (reported in Newtons). Hip external rotation strength of both left and right lower extremity (independently) were moderately correlated with scores on one reach direction (left posteromedial) but not with combined SEBT scores. Overall hip strength and core strength were not correlated with SEBT's composite score.

Wilson et al (2018) also investigated the relationship between components of isometric hip strength and the YBT-LQ. The authors evaluated 40 males and 33 females who were physically active. The authors found significant positive correlations between YBT-LQ and hip abduction strength. They also found correlations between the YBT-LQ and hip extension and external rotation strengths. Linear regression analysis showed hip abduction to be the only significant predictor of Y-Balance performance. In this context, one of the factors which must be pointed out is the training level of the participants between studies. The level of hip strength measures presented a large difference between the current study and Wilson et al (2018) for hip abduction $(15.4 \pm 3.2$ vs. $20.2 \pm 5.1 \mathrm{~N})$, external rotation $(11.1 \pm 2.1$ vs. $6.7 \pm 2 \mathrm{~N})$ and hip extension (20.2 \pm 5.3 vs. $14.5 \pm 4.9 \mathrm{~N}$ ). In the present study, the participants has at least three years of regularly resistance training experience, different to Wilson et al (18) who evaluated participants classified as moderately active in recreational activities.

The relevance of the participants background can be noted in Lee et al (2014) study, which investigated the relationship between YBT-LQ distance and the lower-limb strength of adult women aged 45 to 80 years. Participants were tested for maximal muscle strength of the lower limbs (hip extensors, hip flexors, hip abductors, knee extensors, knee flexors, and ankle dorsiflexors) and YBT-LQ distances in the anterior, posteromedial, and posterolateral directions. The authors noted a weak correlation between lower-limb strength (hip extensors, hip abductors, and knee flexors) and dynamic postural control as measured by the YBT-LQ. In another study Lee et al (2015) investigated the ability of the YBT-LQ and lower limb strength to discriminate between females in two age groups, the relationship between YBT-LQ distance and the Berg Balance Scale (BBS), and the degree to which performance on YBT-LQ distance is related to lower limb strength in middle-aged and older females. The YBT-LQ distance in three directions and lower limb muscle strength for both lower limbs were 
significantly lower in the older adults than in the middle-aged group. A moderate correlation but insignificant correlation was found between the YBT-LQ composite and the BBS scores. In the older females, YBT-LQ distance was significantly positively correlated with strength of the knee flexor and hip abductor. In the middle-aged group, YBT-LQ distance was significantly positively correlated with strength of the knee flexor and hip extensor. This collection of evidence shows controversial results.

It's important to highlight that the intervention was proposed using a modified version of the YBT-LQ using a fixed tape on the floor which can lead the individuals to different neuromuscular strategies in order to maintain their balace. For instance, Jagger et al (2020) aimed to investigate if reach distances were similar during different dynamic stablity tests, a modified Star Excursion Balance Test, a modified version of the Y Balance Test and the Y Balance Test in a sample composed of young and healthy individuals of both sexes finding differences between in all the three directions proposed in our study suggesting caution when comparing different studies.

\section{Final Considerations}

There are important limitations in this study. First, we only tested healthy females with resistance training background. The healthy participants in the study conducted byLee et al (2015) had an average age of 65.73 years, while the moderate physically active participants in the study by Wilson et al (18) had an average age of 25.40 yosin the healthy participants in this study. This suggests that the age of the participant could play a larger role than their injury status and explain the discrepancy seen between correlations amongst the studies. However, the useof healthy subjects decreased the possibility that lower extremity pathology such as patellofemoral pain, ankle instability, or other limitations would prevent maximal performance.

Furthermore, the present findings provide clinicians with useful information regarding the relative contribution of hip muscle strength to YBT-LQ performance when evaluating dynamic balance in resistance training field. Further studies are needed to determine the clinical utility of this test in different age groups or injury conditions. All things considered, the main finding of the current research was the strong association observed between hip external rotators strength and composite score of YBT-LQ. A weak or moderate association was noted between hip flexion, extension, adduction, abduction and internal rotation isometric strength and YBT-LQ reach distances or composite score.

\section{References}

Brech, G., Alonso, A., Luna, N., \& Greve, J. (2013). Correlation of postural balance and knee muscle strength in the sit-to-stand test among women with and without postmenopausal osteoporosis. Osteoporosis International, 24(7), 2007-2013.

Chen, T., \& Chou, L. (2017). Effects of Muscle Strength and Balance Control on Sit-to-Walk and Turn Durations in the Timed Up and Go Test. Archives Of Physical Medicine And Rehabilitation, 98(12), 2471-2476.

Cohen, J. (2013). Statistical Power Analysis for the Behavioral Sciences. Elsevier Science.

Culiver, A., Garrison, J., Creed, K., Conway, J., Goto, S., \& Werner, S. (2019). Correlation Among Y-Balance Test-Lower Quarter Composite Scores, Hip Musculoskeletal Characteristics, and Pitching Kinematics in NCAA Division I Baseball Pitchers. Journal Of Sport Rehabilitation, $28(5), 432-437$.

Douma, R., Soer, R., Krijnen, W., Reneman, M., \& van der Schans, C. (2014). Reference values for isometric muscle force among workers for the Netherlands: a comparison of reference values. BMC Sports Science, Medicine And Rehabilitation, 6(1).

Ganesh, G., Chhabra, D., Pattnaik, M., Mohanty, P., Patel, R., \& Mrityunjay, K. (2015). Effect of trunk muscles training using a star excursion balance test grid on strength, endurance and disability in persons with chronic low back pain. Journal Of Back And Musculoskeletal Rehabilitation, 28(3), 521530.

Gordon, A. T., Ambegaonkar, J. P., \& Caswell, S. V. (2013). Relationships between core strength, hip external rotator muscle strength, and star excursion balance test performance in female lacrosse players. International journal of sports physical therapy, 8(2), 97-104.

Hartley, E. M., Hoch, M. C., \& Boling, M. C. (2018). Y-balance test performance and BMI are associated with ankle sprain injury in collegiate male athletes. Journal of science and medicine in sport, 21(7), 676-680. 
Research, Society and Development, v. 10, n. 10, e327101019167, 2021

(CC BY 4.0) | ISSN 2525-3409 | DOI: http://dx.doi.org/10.33448/rsd-v10i10.19167

Hopkins, W. G., Marshall, S. W., Batterham, A. M., \& Hanin, J. (2009). Progressive statistics for studies in sports medicine and exercise science. Medicine and science in sports and exercise, 41(1), 3-13.

Jagger, K., Fazier, A., Aron, A. \& Harper, B. (2020). Scoring performance variations between the Y-Balance Test, a modified Y-Balance test, and the modified Star Excursion Balance Test. International journal of sports physical therapy, 15(1), 34-41.

Johnston, W., Dolan, K., Reid, N., Coughlan, G. F., \& Caulfield, B. (2018). Investigating the effects of maximal anaerobic fatigue on dynamic postural control using the Y-Balance Test. Journal of science and medicine in sport, 21(1), 103-108.

Kendall, F. (2005). Muscles testing and function. Williams \& Wilkins.

Lee, D. K., Kim, G. M., Ha, S. M., \& Oh, J. S. (2014). Correlation of the Y-Balance Test with Lower-limb Strength of Adult Women. Journal of physical therapy science, 26(5), 641-643.

Lee, D. K., Kang, M. H., Lee, T. S., \& Oh, J. S. (2015). Relationships among the Y balance test, Berg Balance Scale, and lower limb strength in middleaged and older females. Brazilian journal of physical therapy, 19(3), 227-234.

Linek, P., Sikora, D., Wolny, T., \& Saulicz, E. (2017). Reliability and number of trials of Y Balance Test in adolescent athletes. Musculoskeletal science \& practice, $31,72-75$.

Medronho, R., Vergetti Bloch, K., Raggio Luiz, R., \& Loureiro Werneck, G. (2009). Epidemiologia (2nd ed.). Atheneu.

McCann, R. S., Crossett, I. D., Terada, M., Kosik, K. B., Bolding, B. A., \& Gribble, P. A. (2017). Hip strength and star excursion balance test deficits of patients with chronic ankle instability. Journal of science and medicine in sport, 20(11), 992-996.

Paz, G. A., Maia, M., Farias, D., Santana, H., Miranda, H., Lima, V., \& Herrington, L. (2016). Kinematic analysis of knee valgus during drop vertical jump and forward step-up in young basketball players. International journal of sports physical therapy, 11(2), $212-219$.

Paz, G. A., Gabbett, T. J., Maia, M. F., Santana, H., Miranda, H., \& Lima, V. (2017). Physical performance and positional differences among young female volleyball players. The Journal of sports medicine and physical fitness, 57(10), 1282-1289.

Riemann, B. L.; Lephart, S. M. (2002). The sensorimotor system, part 1: the physiologic basis of functional joint stability. Journal of athletic training, $37(1), 71-79$.

Williams, V. J., Nagai, T., Sell, T. C., Abt, J. P., Rowe, R. S., McGrail, M. A., \& Lephart, S. M. (2016). Prediction of Dynamic Postural Stability During Single-Leg Jump Landings by Ankle and Knee Flexibility and Strength. Journal of sport rehabilitation, 25(3), 266-272.

Wilson, B. R., Robertson, K. E., Burnham, J. M., Yonz, M. C., Ireland, M. L., \& Noehren, B. (2018). The Relationship Between Hip Strength and the Y Balance Test. Journal of sport rehabilitation, 27(5), 445-450. 